\title{
Toll-Like Receptor 3 Immune Deficiency May Be Causative for HSV-2-Associated Mollaret Meningitis
}

\author{
Olaf Willmann $^{\mathrm{a}} \quad$ Parviz Ahmad-Nejad $^{\mathrm{b}} \quad$ Michael Neumaier $^{\mathrm{b}} \quad$ Michael G. Hennerici ${ }^{\mathrm{a}}$ \\ Marc Fatara \\ a Department of Neurology, and ${ }^{\mathrm{b}}$ Institute of Clinical Chemistry, Universitätsmedizin Mannheim, \\ University of Heidelberg, Mannheim, Germany
}

Dear Sir,

A 47-year-old man without fever was referred to our neurology department with cumulative headache, sensitivity to light and neck stiffness since the previous day. On the day of admission, nausea occurred and the patient had vomited several times. At this time point headache was most intense and he described the impression of water rushing in his ears. The patient had already experienced two similar episodes diagnosed as meningitis 3 and 6 years before. Several years prior to the first episode, he remembered untreated small genital blisters with spontaneous recovery. An infectious focus in the ear, nose or throat could not be determined; there was also no history of any other disease, like migraine, head trauma, any relation to drug treatment or a stay abroad. Beside his neck stiffness physical and neurologic examination was always normal - as it was on admission. No skin lesions were obtained. A spinal and cerebral MRI (1.5 T using T1, T2, $\mathrm{T}^{*}$ and DWI sequences including MR angiography) showed neither structural lesions nor meningeal enhancement. Lumbar puncture confirmed the diagnosis 'vi-

O. Willmann and P. Ahmad-Nejad contributed equally. ral meningitis'. Early cytology showed the characteristics, but not specific mononuclear endothelial Mollaret cells (fig. 1). Laboratory findings of cerebrospinal fluid (CSF) using enzyme-linked immunosorbent assay (ELISA), chemiluminescent immunoassay (CLIA), Western blot or polymerase chain reaction (PCR) for a pathogenic agent (e.g. Mycobacterium tuberculosis, Borrelia burgdorferi, enteroviruses, herpes simplex type 1, human herpes type 6, cytomegalovirus, varizella zoster, EpsteinBarr, mumps, human immunodeficiency virus and Cryptococcus) were negative. There was no sign of a systemic disease or CSF shunt.

History of CSF is presented in table 1. HSV-specific PCR revealed a positive result for herpes simplex virus type 2 (HSV2) in all three episodes with acute symptoms during the first 2 days. Genotyping for functionally relevant sequence variations in the toll-like receptor 3 (TLR-3) and the UNC-93B genes which have previously been associated with susceptibility to herpes simplex encephalitis revealed the homozygous Phe variant (encoded by the T allele at rs3775291) for TLR3 p.Leu412Phe (p.L412F) by pyrosequencing [1-3]. No other sequence variation investigated (TLR3 p.Asn284Ile, TLR3 p.Pro554Ser, UNC-93B 1034 del 4 or $781 \mathrm{G}>\mathrm{A}$ ) could be detected.
All episodes were treated with intravenous acyclovir $3 \times 10 \mathrm{mg} / \mathrm{kg} /$ day for two weeks and the headache relieved continuously during the first 4-5 days of treatment. After the third actual presentation, we started a prophylactic medication with valacyclovir $500 \mathrm{mg} /$ day. Since then, normal CSF results were found for 6 months. The prophylactic on-going medication was well tolerated without any side effects.

\section{Discussion}

Recurrent lymphocytic meningitis was first described and named by Pierre Mollaret in 1944 and clinical and diagnostic criteria allowed the diagnosis in our case [4]. Besides the CSF pleocytosis with characteristic mononuclear endothelial cells nucleic acid testing revealed a positive result for HSV-2. HSV-2 is known to induce recurrent meningitis as it was the case in our patient $[5,6]$. Cases without fever were also reported earlier by Galdi et al. [7]. Other agents causing recurrent meningitis or a systemic disease such as systemic lupus erythematodes or spinal or cerebral lesions were not identified in our case.

Since molecular biology-based methods have become widely used, the number of HSV-2-positive Mollaret meningitis patients have increased. Dylewski et al. [8]

\section{KARGER}

Fax +4161306 1234 E-Mail karger@karger.ch www.karger.com
(C) 2010 S. Karger AG, Base 0014-3022/10/0634-0249\$26.00/0

Accessible online at:

www.karger.com/ene
O. Willmann, MD

Department of Neurology, Universitätsmedizin Mannheim, University of Heidelberg Theodor-Kutzer-Ufer 1-3, DE-68167 Mannheim (Germany)

Tel. +49621383 2885, Fax +496213833807

E-Mail o.willmann@neuro.ma.uni-heidelberg.de 


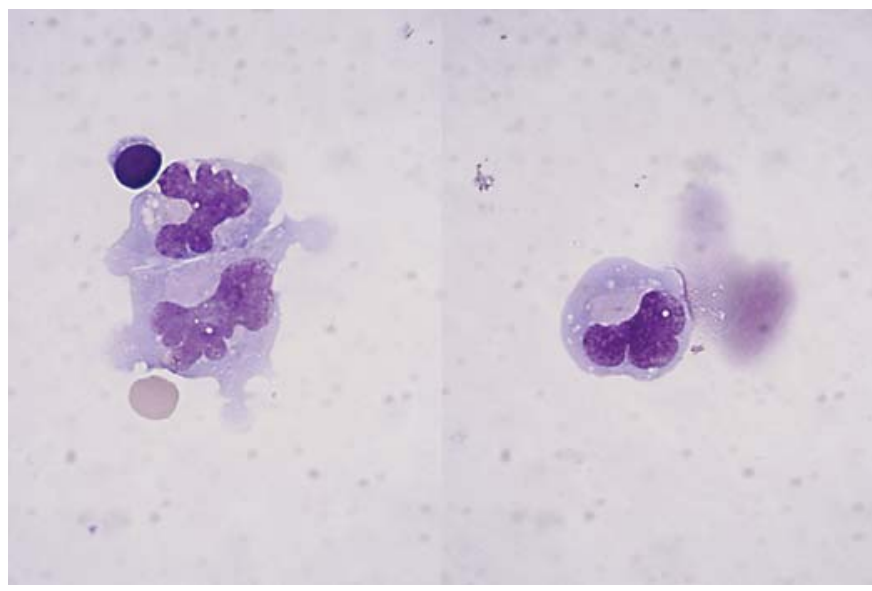

Fig. 1. May-Grunwald-Giemsa staining of CSF shows large monocytes with pseudopods and bean-shaped bilobed nuclei sometimes presenting in aggregates.
Table 1. History of CSF results

\begin{tabular}{|c|c|c|c|c|}
\hline $\begin{array}{l}\text { Follow-up } \\
\text { days }\end{array}$ & $\begin{array}{l}\text { Cells } \\
\mathrm{n} / \mu \mathrm{l}[0-5]\end{array}$ & $\begin{array}{l}\text { Protein, mg/l } \\
\text { [150-450] }\end{array}$ & $\begin{array}{l}\text { Glucose } \\
\mathrm{mg} / \mathrm{dl}[45-70]\end{array}$ & $\begin{array}{l}\text { HSV-2 } \\
\text { PCR }\end{array}$ \\
\hline \multicolumn{5}{|c|}{ First episode at 41 years of age } \\
\hline 0 & 353 & 872 & 64 & positive \\
\hline 6 & 195 & 273 & 61 & negative \\
\hline 9 & 15 & 204 & 59 & negative \\
\hline \multicolumn{5}{|c|}{ Second episode at 44.5 years of age } \\
\hline 0 & 555 & 857 & 60 & positive \\
\hline 12 & 57 & 280 & 52 & negative \\
\hline 60 & 19 & 287 & 62 & negative \\
\hline 90 & 9 & 303 & 58 & negative \\
\hline \multicolumn{5}{|c|}{ Third episode at 47.5 years of age } \\
\hline 0 & 582 & 1,325 & 50 & positive \\
\hline 10 & 169 & 357 & 53 & positive \\
\hline 45 & 14 & 292 & 56 & negative \\
\hline 180 & 1 & 312 & 61 & negative \\
\hline
\end{tabular}

demonstrated 49 (84\%) HSV-2-positive cases in a collective review of 58 patients with recurrent lymphocytic meningitis. A recent study reviewing 49 patients with HSV-2 affecting the central nervous system revealed $43(88 \%)$ meningitis cases of which 8 (19\%) patients had recurrent lymphocytic meningitis [9].

The phenomenon why patients suffer recurrence of meningitis instead of genital herpes or vice versa or both might be explained by genetic aspects or different virus strains. TLR3 is located primarily in intracellular vesicles of many cells and recognizes double-stranded virus RNA and polyinosine-polycytidylic acid (poly I:C), a synthetic double-stranded RNA analogue predominantly used in studies [10]. TLR3 triggering can induce innate immune responses by stimulating the production of interferons and activating a variety of cytokines and chemokines. The nonsynonymous and frequent p.L412F sequence variation is present in around $20 \%$ of the human population. Biochemically the p.L412F displayed a reduced receptor activ- ity upon stimulation which could not be restored by increasing poly I:C concentrations [3]. By analyzing p.L412F sequence variation, our patient was homozygous for this allele. We therefore postulate a deficient immune response against HSV-2, because TLR3 is vital for natural immunity in HSV-1 encephalitis patients and TLR 3 agonists are known to elicit protective immune response for genital HSV-2 infection $[1,11]$.

Our patient had only one suspicious untreated episode of genital herpes before the onset of recurrent meningitis, although asymptomatic episodes are known of in HSV-2. Aurelious et al. [12] suggested that the absence of apparent genital infection may be the more common presentation at the time of meningeal involvement. In accordance with other reports our patient experienced a quick recovery of symptoms and long symptom-free intervals by acute intravenous treatment with acyclovir. Some experts doubt the need of treatment according to known spontaneous benign course with long symptom-free intervals and regarded long-term antiviral prophylaxis not to be appropriate, but it could be a beneficial option in cases with high frequency [13]. For prophylaxis, we chose oral valacyclovir therapy known to be effective in suppression of recurrent genital herpes [14]. Under this treatment for 22 months the patient developed no further meningitis so far. But how long a prophylactic treatment should be given and when a complete eradication of HSV2 in the central nervous system could be achieved still remains unclear.

\section{Conclusion}

In this case report, we demonstrate a patient with recurrent lymphocytic meningitis, who suffered from deficiency in TLR3 due to homozygous p.L412F sequence variation (encoded by the $\mathrm{T}$ allele at rs3775291). To gain further information on the possible relevance of TLR3 deficiency for recurrent lymphocytic meningitis, TLR3 alleles should be tested in such cases.
References
Zhang SY, Jouanguy E, Ugolini S, et al: TLR3 deficiency in patients with herpes simplex encephalitis. Science 2007;317:1522-1527.

2 Casrouge A, Zhang SY, Eidenschenk C, et al: Herpes simplex virus encephalitis in human UNC-93B deficiency. Science 2006;314:308312.
3 Ranjith-Kumar CT, Miller W, Sun J, et al: Effects of single nucleotide polymorphisms on Toll-like receptor 3 activity and expression in cultured cells. J Biol Chem 2007;282: 17697-17705.

4 Mollaret P: La méningite endothélioleucocytaire multirécurrente bénigne syndrome nouveau ou maladie nouvelle? Rev Neurol (Paris) 1944;76:57-67. 
5 Shalabi M, Whitley RJ: Recurrent benign lymphocytic meningitis. Clin Infect Dis 2006;43:1194-1197.

6 Kupila L, Vainionpää R, Vuorinen T, Marttila RJ, Kotilainen P: Recurrent lymphocytic meningitis: the role of herpesviruses. Arch Neurol 2004;61:1553-1557.

7 Galdi AP: Benign recurrent aseptic meningitis (Mollaret's meningitis): case report and clinical review. Arch Neurol 1979;36:657658.
8 Dylewski JS, Bekhor S: Mollaret's meningitis caused by herpes simplex virus type 2: case report and literature review. Eur J Clin $\mathrm{Mi}$ crobiol Infect Dis 2004;23:560-562.

$\checkmark 9$ Omland LH, Vestergaard BF, Wandall JH: Herpes simplex virus type 2 infections of the central nervous system: a retrospective study of 49 patients. Scand J Infect Dis 2008;40: 59-62.

10 Alexopoulou L, Holt AC, Medzhitov R, Flavell RA: Recognition of double-stranded RNA and activation of NF-kappaB by Tolllike receptor 3. Nature 2001;413:732-738.

11 Gill N, Davies EJ, Ashkar AA: The role of toll-like receptor ligands/agonists in protection against genital HSV-2 infection. Am J Reprod Immunol 2008;59:35-43.
2 Aurelius E, Forsgren M, Gille E, Sköldenberg B: Neurologic morbidity after herpes simplex virus type 2 meningitis: a retrospective study of 40 patients. Scand J Infect Dis 2002; 34:278-283.

13 Tyler KL: Herpes simplex virus infections of the central nervous system: encephalitis and meningitis, including Mollaret's. Herpes 2004;11(suppl 2):57A-64A.

14 Wald A, Selke S, Warren T, Aoki FY, Sacks S, Diaz-Mitoma F, Corey L: Comparative efficacy of famciclovir and valacyclovir for suppression of recurrent genital herpes and viral shedding. Sex Transm Dis 2006;33:529-533. 